\title{
Post Secondary Students' Level of Proficiency in Solving Real World Problems in Mathematics
}

\author{
Lorinda E. Pascual1, Anthony B. San Pedro² \\ ${ }^{1}$ College of Engineering, Nueva Ecija University of Science and Technology, Cabanatuan City, Philippines \\ ${ }^{2}$ Department of Public Administration, Nueva Ecija University of Science and Technology, Cabanatuan City, Philippines \\ Email:lorindapascual@yahoo.com, anthonybasasanpedro@yahoo.com
}

How to cite this paper: Pascual, L.E. and San Pedro, A.B. (2018) Post Secondary Students' Level of Proficiency in Solving Real World Problems in Mathematics. Journal of Applied Mathematics and Physics, 6, 198-214.

https://doi.org/10.4236/jamp.2018.61019

Received: December 27, 2017

Accepted: January 23, 2018

Published: January 26, 2018

Copyright $\odot 2018$ by authors and Scientific Research Publishing Inc. This work is licensed under the Creative Commons Attribution International License (CC BY 4.0).

http://creativecommons.org/licenses/by/4.0/

\begin{abstract}
The problem solving competency is the primary goal in all mathematics education curricula. It is acquired by solving mathematical problems belonging either to routine or non-routine category. The study describes the post-secondary students' levels of proficiency in solving non-routine math problems. The three-stage process in solving mathematics problems by Mayer was used as the frame of analysis. Using the data generated from researcher made instruments, and semi-structured interview of 50 purposively selected participants, the study found that: Majority of the participants showed "good proficiency" in "problem representation" and "problem solving", the real world problems in Math. It is also revealed that those who are good in problem representation phase are also good in problem solution phase. In general, participants do not always consider answer verification phase as important in the process of solving real world problems in math. The most common difficulties encountered by participants are: language inadequacy and unfamiliarity with the context of the problems. The researchers recommended that the same study be done in some other context and local and if the results are consistent with this study, may consider redesigning new curriculum in post-secondary mathematics education.
\end{abstract}

\section{Keywords}

Mathematics, Post-Secondary Students, Problem Solving

\section{Introduction}

Problem solving competency is the primary goal in the mathematics education curriculum. It is the acquisition of increased levels of problem solving competency which provides a basis for future learning, effective participation in society 
and for conducting daily activities. It is a skill needed to surmount challenges and difficulties faced in life. However, despite its importance, the [1], an international organization of mathematics educators, argued that solving problems is not only a goal of learning mathematics, but also a major means of doing so. The development of students' ability to solve mathematical problems is the primary objective of instruction and how to reach this goal remains to be the problem of education. Teachers are encouraged to use a wide variety of strategies to be able to develop students' problem solving abilities. Problem solving competency is a dynamic process in which students try to understand the solution, make a plan for the solution, select or develop methods and strategies and apply all these heuristics to obtain the solution [2].

Problem solving competency is acquired by solving mathematical problems belonging to either routine or non-routine categories. Routine problems can be solved by the application of rules, procedures and basic operations that the problem solver already know [3] while solving non routine problems requires innovative and creative strategies. These are heuristics or problem solving procedures that do not guarantee a solution to a problem but provide a more highly probable method for discovering the solution to a problem [4]. More often than not, little or no algorithm is used on this problem category. With specific focus on non-routine problems, students find difficulties solving them because they do not have a straight forward solution. They require creative and critical thinking, employing alternative approaches and various heuristics to solve the problems [5]. To enhance the problem solving skills of students, teachers can expose them to world problems that challenge their heuristics. These problems can provide them a large room for varied solutions, strategies and alternatives. One type of non-routine problem includes real world problems [6]. Their solutions require giving particular attention to real-life contexts related to the problems. Students need to utilize their intuitive knowledge and daily life experiences to solve real world problems [7]. They provide an opportunity to apply mathematical knowledge to real world situations [8]. It is for this reason why educators suggest that real world problems should be incorporated into the teaching of mathematics.

This idea of teaching and learning through real life problems follows the National Council for Teaching Mathematics (NCTM) principles of learning and assessment. Students are building on the knowledge they had already gained and putting it towards new applicable life problems. Solving problems based on real life also builds upon all of the process standards. The student is building new mathematical knowledge through problem solving. He is using reasoning and makes connections through what they had learned in class and the problem he is presently encountered. It is the goal of every teacher; to teach and guide students develop knowledge and skills necessary to solve real world problems in mathematics.

Non-routine problems are considered more complicated and difficult than routine problems. They seem to present other difficulties for the problem solver than standard problems do. Unfortunately, there is little information about what 
challenges and obstacles students encounter when solving real-world problems posed by non-routine math problems.

Based on the foregoing premises, the study explores into the strategies employed by post-secondary students in solving non-routine problems in mathematics. It is hoped that the identified strategies in solving non-routine world problems emerging from the results of the study may provide a frame of reference to design a new curriculum adaptive to students' competence in solving problems in mathematics.

\subsection{Objectives of the Study}

This study was conducted to describe the students' level of proficiency and process used in solving real world problems. The main objectives of the study are as follows:

1) Describe the problem solving process employed by the students in the following problem solving phases:

a) problem representation;

b) problem solution, and;

c) answer verification.

2) Qualitatively measure the post-secondary students' levels of proficiency in solving real world problems.

3) Identify the students' difficulties in solving real world problems

\subsection{Theoretical Framework}

The theoretical framework of the study revolves around the math problem solving process by [9]. Mayer believes that problem solving process consists of two major parts, namely 1) Problem Representation, and 2) Problem Solution. For this study answer verification was included as part of the problem solving process. Figure 1 shows the paradigm of the study.

The process begins when a student is given a non-routine word problem to solve. There are three major phases involved in solving a non-routine problem: representation, problem solution, and answer verification. The first phase, problem representation is composed of two sub-stages: problem translation, which relies on linguistic skills needed to comprehend what the problem is saying, and problem integration, which depends on the ability to mathematically interpret the relationships among the problem parts to form a structural representation. The first sub-stage, problem translation, is synonymous with paraphrasing, and the second sub-stage, problem integration, may correspond to visual representation.

Problem solution, the second phase, is composed of the sub-stages solution planning, determining what operations are used and the order in which to use them. This phase also includes the strategy that the students employ in solving the problem. The solution execution, is carrying out the planned computations in order to solve the problem. The correct solution depends on the accuracy of each of the preceding sub-stages. 


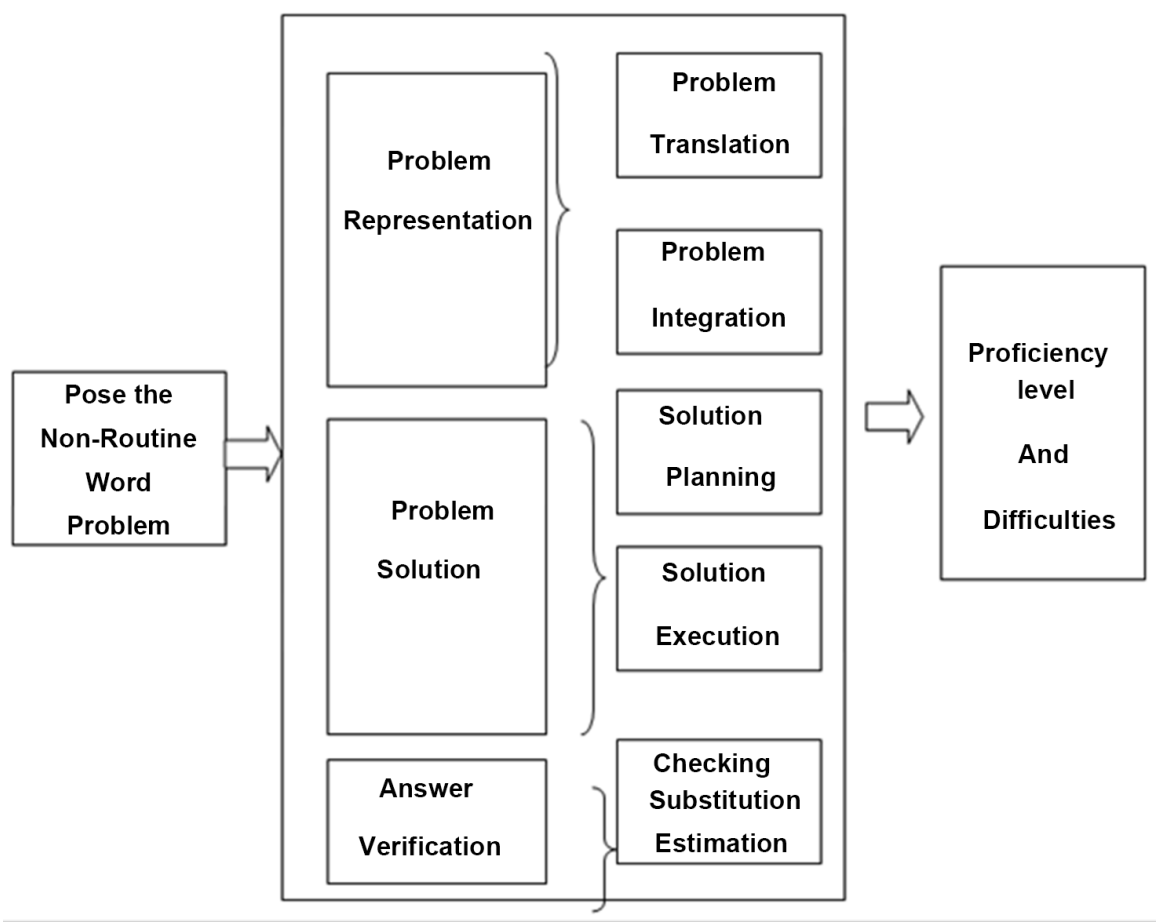

Figure 1. Research paradigm.

The third phase, answer verification is where the student checks the result and sees the plausibility of the strategies used in the problem solving process. This step may also tell the mistakes committed if there are any.

The students' proficiency levels and difficulties in solving non-routine problems were evaluated and analyzed in terms of the problem solving strategies that they employed in the different stages of the problem solving process.

\section{Methodology}

The descriptive-qualitative type of research design was used in the study in order to generate data relevant to the description and analysis of post-secondary students' proficiency levels and strategies in solving real world problems.

\subsection{Research Locale}

The study was conducted at the Nueva Ecija University of Science and Technology (NEUST), Cabanatuan City. NEUST operates in several campuses namely, the Gen. Tinio Campus, the Sumacab Campus, the San Isidro Campus, the Fort Magsaysay Campus, the Atate Campus, Gabaldon Campus, the NEUST North and South extension campuses and the Cyber Campus in Hongkong, Taiwan and Macau. The study was specifically conducted at the Sumacab and General Tinio campuses only.

\subsection{Participants}

The participants to this study were composed of 50 post-secondary school students enrolled in different programs at the Nueva Ecija University of Science 
and Technology (NEUST) during the second semester of academic year 2015-2016. The students came from the Colleges of Industrial Technology, Agriculture, Education, Management and Business Technology and Communications and Information Technology. Purposive sampling was used by the researcher in selecting ten students from each College. The criteria set for selection of ten participants from each academic unit are as follows: a) enrolled in the first year of post-secondary level; b) have enrolled and finished the subject Algebra; c) willing to participate in the study; d) belong to the categories of ability set by the researchers based on their grades in Algebra. In this regard the following numerical grades are applied: Low: 3.0 to 2.75; Average: 2.74 - 2.0; and High 1.99 to 1.0. The selected participants were then grouped based on these range of averages.

\subsection{The Instruments}

The data used in the study were obtained using two instruments, real world problems worksheets, and interview guide.

1) Real World Problems

The set of problems was composed of six (6) real world problems adapted from the works of various researchers [10] [11] [12]. The researcher initially selected twelve (12) non-routine real word problems taken from mathematics books, dissertations and internet sources with some modifications to meet the local setting of the study. The twelve (12) problems were administered to randomly chosen 20 post secondary engineering and education students to determine the clarity and difficulty of the problems. Problems which were found very difficult and very easy to solve were discarded. A total of six problems were chosen based on the result of the trial, some problems were reworded using simpler words. The six problems selected were also shown to other mathematics teachers for comments and suggestions.

2) Interview Guide

The semi-structured interview guide consists of a list of questions asked to clarify the thoughts of the students on the process they used in solving the non-routine real world problems. Questions on the students' sources of difficulties in solving the non-routine problems were also included in the interview guide.

\subsection{Analysis of Data}

The researchers employed qualitative techniques in describing the process used by the students in the problem solving. The "noting details" was also used. The written solution to each problem in the worksheets was identified and analyzed. The transcripts of the interview conducted to the students were also included in describing the heuristics of the students in the entire problem solving process.

In describing problem representation, the medium used like equations, drawings designs and the like was identified and graded accordingly as to the level of 
proficiency based on proficiency table. Meantime the description of the level proficiency in problem solution or the plan and execution of the strategy was described whether it is correct or incorrect. The strategies enumerated from the works of [13] and by [14] are applied such as:

1) Writing down a mathematical statement involving one or more operations on the numbers given in the problem.

2) Setting up an equation involving the use of one or more unknown as variables and equation (s).

3) Making a model or diagram includes use of objects or drawings.

4) Making a table includes organizing the data by making a table.

5) Making a list includes organizing the data by a making a list.

6) Using a formula for the problem situation.

7) Guessing, checking and revising involve making a reasonable guess, checking the guess, and revising the guess, if necessary.

8) Looking for patterns involves determining certain common characteristics that can be generalized and used to solve the problem.

9) Employing proportional properties (direct and inverse).

10) Self-invented strategy involves the method constructed by the students other than the algorithmic and procedural strategies taught to them.

To describe the students' level of proficiency in solving real world problems, the levels of proficiency and descriptors used are presented in table. Meanwhile, answer verification observed by students was described using the proficiency table (Table 1) and descriptors assigned to each level. Answer verification is the method or manner of checking the soundness or correctness of the answer when obtained.

Finally, the difficulties encountered by the students in solving non-routine problems were identified by examining their written solution and semi- structured interview.

\subsection{Procedure of the Study}

The procedure of the study has three stages.

\section{Stage 1. Before the Administration of the Instruments}

Prior to the administration of the instruments, the researcher sought permission from the College Deans to administer the instruments to their selected students. Proper coordination with the subject teachers was made on the administration of the instruments. A schedule of administration was prepared for the different colleges.

\section{Stage 2. Actual Administration of the Instruments}

The subject teachers of the chosen students gathered them in a room. The subject teacher introduced the researcher to them and allowed her to explain the purpose of the study. The researcher properly instructed the students on what to do. It was also explained to them that the results of their work will not in any way affect their grades in mathematics. To keep the anonymity of their identity, 
Table 1. Proficiency table.

\begin{tabular}{|c|c|c|c|}
\hline \multirow{2}{*}{$\begin{array}{c}\text { Level of } \\
\text { Proficiency }\end{array}$} & Problem Representation & Problem Solution & Answer Verification \\
\hline & Descriptors & Descriptors & Descriptors \\
\hline Good & $\begin{array}{l}\text { The problem representation is } \\
\text { correct. The details of the } \\
\text { information given in the } \\
\text { problem are complete. }\end{array}$ & $\begin{array}{l}\text { The plan to the solution of } \\
\text { the problem is evident. The } \\
\text { execution of the solution } \\
\text { and the answer obtained } \\
\text { are correct. }\end{array}$ & $\begin{array}{l}\text { The method of answer } \\
\text { verification is evident } \\
\text { and clearly explained. }\end{array}$ \\
\hline Mediocre & $\begin{array}{c}\text { The problem representation } \\
\text { is correct but some } \\
\text { important details are } \\
\text { missing. }\end{array}$ & $\begin{array}{l}\text { The plan to the solution of } \\
\text { the problem is not evident. } \\
\text { Some flaws in the execution } \\
\text { of the plan are noted. } \\
\text { Answer obtained is correct }\end{array}$ & $\begin{array}{c}\text { The method of answer } \\
\text { verification was evident } \\
\text { but explanation given is } \\
\text { incorrect. }\end{array}$ \\
\hline Poor & $\begin{array}{l}\text { The problem representation is } \\
\text { incorrect. The details of } \\
\text { information in the problem } \\
\text { were not given. }\end{array}$ & $\begin{array}{l}\text { There is no plan in solving } \\
\text { the problem. The answer } \\
\text { obtained is incorrect }\end{array}$ & $\begin{array}{l}\text { There is no attempt to } \\
\text { verify the correctness of } \\
\text { the answer obtained. }\end{array}$ \\
\hline
\end{tabular}

their names were coded. The instruments were personally administered by the researcher. Each problem was completed by the student respondent within the allotted time of not more than thirty minutes. When the student has completed the task, he submits his work to the researcher, and the one-on-one interview followed immediately.

\section{Stage 3. After the Administration of the Instruments}

This stage includes the organization, analysis and interpretation of the data. In the organization of data, an envelope was used to store the students' written works. In the analysis, the worksheets were sorted based on the heuristics that the students employed in solving the problem.

\section{Results and Discussions}

The results on the strategies used by post-secondary students in solving non-routine real world problems provide information on how they can further develop their skills along this area. Non-routine problems are those that appropriately develop reasoning skills as well as the ability to apply these skills to real life situation [15]. In the case of the post-secondary students, the strategies they used in the problem solving process tell what they already know and can do in problem solving, and those which they cannot do. As the real world problems are mostly based on real-life situations, the abilities of using various strategies in solving word problems displayed by the students reveal how well they used their reasoning skills in some real-life situations. The students' experiences on these may help them plan the strategies in the solution of the problems. According to [16], solving a non-routine problem is a cognitively non-trivial task that the problem solver may not know the method of the solution. [17] said that routine problems can be solved using familiar methods using step-by-step fashion while in non-routine problems, there is no predictable, well-research approach or explicitly suggested by the task. In the case of the participants, many tried to employ 
the methods commonly used in solving routine problems like the use of equations and ratio and proportion. Those who used drawings and figures to model the problem situation still ended up using forming an equation or system of equation in representing the problem situations.

In the non-routine problem solving strategies, the procedures and algorithms are explored and analyzed. The pathways to the solution are discovered. As cited by [18] non-routine problem solving strategies include acting the problem out, looking for pattern, making a systematic list, working backwards, guessing and checking, making a drawing or diagram, writing an equation or open sentence, making a table, eliminating the possibilities, using logical reasoning, matrix logic, and estimation. The post-secondary students used a majority of the cited strategies since these strategies apply to both routine and non-routine problems. However, when the students were asked how they use such strategies, most of them said that they just recalled most of the common strategies that they know. With this reason given, it can be inferred that when students are asked to solve problems, they just look back on the strategies that they know early on. For those students, who were not successful in planning the strategies for the solution of the problem, it could be possible that they have nothing to retrieve in their memory or schema. The sad thing is, if the students cannot recall the strategies they learned previously, they tend to give up at once instead of discovering other new strategies. This finding implies that the behavior and attitude of the students relate to their problem solving proficiency. If the students do not develop perseverance and intrinsic motivation in solving problems, this kind of attitude may reflect the response to whatever problems that they may encounter in life.

According to [19], the final step in the problem solving process is checking. The problem solver must check the answer obtained to determine if the goal of the problem is attained. Other things to be checked include the consistency of the solution with units, signs, and values. This final step in the problem solving process on non-routine problems were rarely identified in the case of the first year college students. After obtaining an answer, the process end there. Almost all of the students were observed to have done this in their works. Based on this finding, mathematics teachers should always encourage their students to verify the answer obtained in relation to the goal of the problem. In this way, the students may develop the attitude of always checking the soundness or correctness of answers obtained. The ability to always check the soundness or correctness of an answer obtained in the problem may impact the lives of the students. Say for example, if a student is faced with a real-life situation problem, and the solution and answer has been identified, the soundness of the decision arrived at is established if he has developed the habit of checking all actions taken.

\subsection{Proportion of Students' with Different Levels of Proficiency in Solving Real World Problems}

The proportions of students' with different levels of proficiency in different 
phases of the problem solving process, namely: problem representation, problem solution, and answer verification are described below.

\subsubsection{Proportion of Students' with Different Levels of Proficiency in Problem Representation}

The proportion of students with different levels of proficiency in representing the problem is shown in Table 2, to wit:

In Problem 1, there were 11 participants or 26 percent who have good representation of the problem, 20 participants or 47 percent have mediocre proficiency, and 12 or 28 percent have poor proficiency. Participants who are good in representation were able to note down the pertinent data embedded in the problem. They used correct mathematical representation using system of linear equation and drawings. Those who are mediocre in proficiency, were able to get the system of linear equation representing the problem but committed some errors in labeling the variables. Some did not make labels in the worksheets, but when they were asked what the problem required, they were able to explain the problem using native language in Tagalog. The participants who have written only the given facts in the problem but did not continue with the representation of the problem were considered poor.

In Problem 2, 22 participants or 49 percent were found to have good proficiency in representing the problem. They did this by making a list, use drawings, and form equations. 20 participants equivalent to 44 percent have mediocre proficiency in representing the problem as they were not able to clearly explain how they arrived at using the representation made. The three students with poor proficiency have written some data on the worksheet but no labeling was made. When these students were asked about the problem, they said that "they do not understand it".

In Problem 3, 42 participants got the answer correctly. 22 of 42 displayed good proficiency in representing the problem. The other 20 students presented the problem with mediocrity. In representing the problem, the students use tables, drawings, estimation, and algebraic representation. As for the three students

Table 2. Proportion of students with different levels of proficiency in representing a problem.

\begin{tabular}{ccccc}
\hline \multirow{2}{*}{ Problem Number } & \multirow{2}{*}{$\begin{array}{c}\text { Number of Students who } \\
\text { solve the Problem }\end{array}$} & \multicolumn{2}{c}{ Proportion/Proficiency Levels } \\
\cline { 3 - 4 } 1 & 43 & $11(26 \%)$ & $20(47 \%)$ & $12(28 \%)$ \\
2 & 46 & $25(54 \%)$ & $2(4 \%)$ & $19(41 \%)$ \\
3 & 45 & $22(49 \%)$ & $20(44 \%)$ & $3(7 \%)$ \\
4 & 43 & $23(53 \%)$ & $9(21 \%)$ & $11(26 \%)$ \\
5 & 48 & $31(65 \%)$ & $12(25 \%)$ & $5(10 \%)$ \\
6 & 47 & $14(30 \%)$ & $33(70 \%)$ & $0(0 \%)$ \\
Average & 45 & $21(47 \%)$ & $16(35 \%)$ & $8(18 \%)$ \\
\hline
\end{tabular}


with poor proficiency, they admitted that" they do not understand the problem "so they did not know what to do.

In Problem 4, 23 participants or 53 percent represented the problem with good proficiency. They use drawings, mathematical symbols and equations to represent the problem. Nine students did the same media of representations but minor errors were committed in the labeling of variables. A total of 11 students or 26 percent showed poor proficiency in the problem representation. These students admitted that they had difficulty getting the main idea of the problem.

In problem 5, 31 students out of 48 or 65 percent represented the problem with good proficiency which resulted to correct answer. 12 students or 25 percent did the problem representation with mediocrity. Some representations were not complete, but when they were interviewed they gave the correct representation. In the representation of these students, they made "shortcuts" in their representations. Instead of saying," let $\mathrm{x}$ be the time for the clothes to dry out", they represented as "let $x$ be the time". Majority of the students represented the problem using ratio and proportion. Others use the operation on division. Only five students showed poor proficiency in representing the problem.

In Problem 6, 47 participants answer the problem correctly. Of this number 14 students or 30 percent showed good proficiency in representing the problem using diagrams, and algebraic representations. The 33 or 70 percent almost did the same media of representations but committed only minor errors in labeling the variables. The students did well in this problem.

When described as a whole, nearly one half of the students included in the study showed good proficiency in representing the non-routine problems. This may mean that they have good command of the English language because they have good understanding on the problem context. Those with mediocre proficiency on the problem representation were caused by limited understanding of English language. The representations made were not clear and incomplete. Those who showed poor proficiency in representing the non-routine problems were the results of poor command of English language.

An analysis on the proportion of students with different proficiency levels points on a significant finding causing such proportion of proficiency. The students who showed good proficiency in representing the problem indicate that they have good reading comprehension in texts written in English. For those who did poorly in the representation admitted that they did not understand completely the problem showing poor reading comprehension ability. This result points to the fact that good reading comprehension skills are needed to become good problem solvers.

\subsubsection{Proportion of Students' with Different Levels of Proficiency in Solving the Problem}

Table 3 shows the proportion of students with different levels of proficiency in solving non-routine problems. 
Table 3. Proportion of students with different levels of proficiency in solving the problem.

\begin{tabular}{ccccc}
\hline \multirow{2}{*}{$\begin{array}{c}\text { Problem Number } \\
\text { Number of Students who } \\
\text { Solve the Problem }\end{array}$} & \multicolumn{2}{c}{ Proportion/Proficiency Levels } \\
\cline { 2 - 4 } 1 & 43 & $9(21 \%)$ & $8(19 \%)$ & $26(60 \%)$ \\
2 & 46 & $25(56 \%)$ & $2(5 \%)$ & $19(40 \%)$ \\
3 & 45 & $19(42 \%)$ & $15(33 \%)$ & $11(25 \%)$ \\
4 & 43 & $23(53 \%)$ & $2(5 \%)$ & $18(42 \%)$ \\
5 & 48 & $31(65 \%)$ & $10(21 \%)$ & $7(14 \%)$ \\
6 & 47 & $14(30 \%)$ & $13(28 \%)$ & $20(42 \%)$ \\
Average & 45 & 20 & 8 & 17 \\
\hline
\end{tabular}

In Problem 1, nine students or 21 percent successfully planned the solution of the problem and executed the plan with accuracy. As a result, these students got the correct answer. They used elimination and substitution methods of problem solving.

The few used guess and check method. Eight students or 19 percent used the same strategies but committed some minor errors in the algebraic processes done due to carelessness. 26 participants equivalent to 60 percent did poorly in planning and executing the strategy to solve the problem. 12 of the 26 participants failed to represent the problem correctly, and the other eight students committed errors in carrying out the solution.

In Problem 2, 25 students executed correctly the solution planned to solve the problem. The representation of the problem using drawings, making a list, and systems of linear equations formed were successfully carried out to get the answer to the problem. Hence, these students have good proficiency in their choice of strategies to attain the goal of the problem. One student using the listing method showed mediocre proficiency when he committed a minor error in listing the given data, but he saw this error when he was explaining the solution done, The 40 percent or 19 showed poor proficiency in representing the problem eventually ended up with poor execution of the strategy chosen.

In Problem 3, 19 of the 22 participants who represented the problem rightly got the correct answer. The answer was obtained by applying logical reasoning and performing algebraic operations. Out of 20 students who showed mediocrity in the problem representation, 15 also showed mediocrity in planning and executing the strategies selected. The 11 students who showed proficiency in the problem representation were the same students whose strategies chosen in solving the problem were also good.

In Problem 4, 23 students who showed good proficiency in the problem representation were the same 23 students who carried out their solution strategies with good proficiency. Two students showed mediocrity in carrying out the 
solution strategies planned resulting from the problem representation. 18 students were identified to have displayed poor proficiency in carrying out the problem solution of the problem.

In Problem 5, the 31 students who have shown good proficiency in representing the problem were the same 31 students who carried out their solution strategies with good proficiency. Meanwhile, 10 of the 12 students who showed mediocrity in representing the problem, were also found to have shown mediocrity in the execution of their solution strategies. The two students with mediocre proficiency add up to the five students who have poor proficiency in the problem representation.

In Problem 6, 14 students executed their solution strategies correctly. They used diagrams in problem representation. From the 33 participants who have mediocre proficiency level in representing the problem, 13 of them were found to have mediocre proficiency level in carrying out the solution to the problem. No student was identified to have used poor proficiency in solving the problem.

The results on the data when analyzed, showed that that those with good proficiency in making the correct representation of the problems were almost the same group of participants who have shown good proficiency in carrying out the planned solution strategies to the problem. While those who displayed mediocrity in the execution of the solution strategies were almost the same students who executed the solution strategies of the problem with mediocrity. In the same way, that the students who have shown poor proficiency in the problem representation were the same students who have shown poor proficiency in getting the correct answer to the problem.

The findings of the study seemed to show the link between problem representation and problem solution. This result further implies that the correct answer obtained by the students with good proficiency in problem representation and problem solution did not happen by chance. The students who have shown good proficiency in problem representation and problem solution are students who have the potential to become good problem solvers.

\subsubsection{Proportion of Students' with Different Levels of Proficiency in Answer Verification}

The proportion of students with different levels of proficiency in verifying their obtained answer is shown in Table 4 to wit.

The proportion of students who have shown their proficiency in verifying the answers they obtained reveal surprising result. Even the students who have shown good proficiency in problem representation and problem solution reveal that they are not accustomed of verifying their answers. Many students made answer verification in Problem 2 only. Since majority of the students used ratio and proportion in representing and solving the problem, answer verification was easy to do. But this was not observed in the other problems. This finding indicates that students do not really include answer verification in their problem solving process. 
Table 4. Proportion of students with different levels of proficiency in verifying the answer obtained.

\begin{tabular}{ccccc}
\hline \multirow{2}{*}{ Problem Number } & $\begin{array}{c}\text { Number of Students } \\
\text { who solve the Problem }\end{array}$ & \multicolumn{3}{c}{ Proportion/Proficiency Levels } \\
\cline { 3 - 5 } 1 & 43 & Good & Mediocre & Poor \\
\hline 2 & 46 & $24(52 \%)$ & $2(4 \%)$ & $20(44 \%)$ \\
3 & 45 & $1(2 \%)$ & 0 & $44(92 \%)$ \\
4 & 43 & 0 & 0 & $43(100 \%)$ \\
5 & 48 & 0 & 0 & $48(100 \%)$ \\
6 & 47 & 0 & 0 & $47(100 \%)$ \\
Average & 45 & $9(20 \%)$ & $1(2 \%)$ & $35(79 \%)$ \\
\hline
\end{tabular}

\subsection{Students' Difficulties in Solving Real World Problems}

The difficulties encountered by the post-secondary students are presented based on the strategies they used in solving non-routine problems and their proficiency levels in using these strategies in the different phases of the problem solving process.

\subsubsection{On Problem Representation}

The representation of the problem begins after reading the problem. For some students who have good command of the English language, they understood the problem and can easily make representation of the problem. For those who were not, reading comprehension seemed to hinder them from solving the problem. Some students would say that they do not know how to begin with because they do not understand what the problem was all about. This finding is supported by [20] when he revealed that linguistic difficulty had a significant influence on students' perceptions of the mathematical difficulty of the problem. And English learners lower performance in mathematics reflects the additional cognitive demands associated with text comprehension. The failure of some students to grasp the meaning of the problem may be the result of the complexity of the words in the problem. In the case of the post-secondary student participants to the study, they claimed that they do not understand what the problem was all about, this is indicative of their linguistic difficulty. Many teachers admit that more often than not, they use the native language (Filipino/Tagalog) in explaining concepts, axioms, and theorems in Mathematics. Especially when they felt that the students did not understand what they were explaining. But during assessment, English language is used. Such being the case, there is a clear gap between how lessons are taught and the medium used in assessing learning. If this situation would continue, more and more students would face problem solving difficulties.

Another difficulty of the students is unfamiliarity with the context of real world problems. Some students interviewed and admitted that they have never encountered such kinds of problems during the course of their studies. Since this 
was their first encounter with such kinds of problems they find it difficult to plan the strategies in order to solve the problems.

\subsubsection{On Problem Solution}

The unfamiliarity of the students on the context of real world problems contributed to their difficulty in planning the solution of the problem. As they were not always been exposed to these problem contexts, they have not mastered planning and executing the solution to the problems.

During personal observations, students during planning to solve the problem, tried to apply the procedural methods like use of algebraic symbols and equations. It seems that to some students, they believed that these strategies work to all kinds of problems. When the solution strategy they retrieved from their schema did not work, they did not attempt to try other strategies. This finding implies that many of the students have limited knowledge on the other strategies used in problem solving. This could be due to their irregular and less frequent exposure to non-routine problem contexts.

The difficulty of students in problem representation is carried over to their difficulty in planning out the strategy to be used in solving the non-routine problem.

\subsubsection{On Answer Verification}

The difficulty of students in verifying the correctness of their answers is not conclusive for the reason that most students do not verify the correctness of the answers they obtained. The finding found was that majority of the students did not develop the habit of checking their answers.

Problem solving is a process. If a problem solver fails in the initial process of understanding the problem, the succeeding steps in the process like problem representation, problem solution, and answer verification would be useless.

\section{Conclusions/Recommendation}

\subsection{Conclusions}

In the light of the findings of the study, the following conclusions are drawn.

1) The students' abilities to represent the context of the problems are due to poor reading comprehension resulting from their poor command of the use of the English language.

2) The students' minimal exposure and familiarity to the context of real world problems may have caused their inability to plan and execute the strategies in solving the non-routine problems.

3) Very few students develop the habit of verifying the correctness of the answers obtained.

4) The students' problem representations were carried over to their planning and execution of the solution strategies. Students who have good proficiency in representing the context of the problems easily constructed the solution strategies to obtain the answer to the problems. Likewise, those who have poor proficiency 
in representing the problem have also showed poor proficiency in planning their solution strategies.

5) The proportion of good, mediocre, and poor problem solvers is dependent on their ability to comprehend the problem.

6) Students' difficulty in using problem solving strategies in real world problems may have come from their poor reading comprehension skills and unfamiliarity of the contexts of real world problems.

\subsection{Recommendations}

In view of the findings and conclusions drawn from the study, the following recommendations are offered.

1) To encourage mathematics teachers on the least or minimal use of the native language (Tagalog) as the medium of instruction in their mathematics classes. Printed learning materials in mathematics are all written in English, so students may have difficulty comprehending word problems in English if they are taught in Tagalog.

2) To include non-routine or real-life situation problems in problem solving lessons of students so that students get familiar with other contexts of problems;

3) To teach students the importance of answer verification to problem solving task as it ensures the correctness and accuracy of answers obtained.

4) To revisit the contents of instructional materials used by teachers and students in teaching and learning mathematics subjects particularly in solving word problems and the connections between problem representation and problem solution;

5) To encourage mathematics teachers and administrators to design programs and activities that will improve their command on the use of the English language;

6) To encourage mathematics teachers to identify and recommend solutions to ease the difficulties of students in solving routine and non-routine problems.

7) To encourage other researches to conduct another study along this area to find other relevant findings causing students' difficulty in solving word problems.

\section{References}

[1] National Council of Teachers of Mathematics (2000) Principles and Standards for School Mathematics. NCTM, Reston, VA.

[2] Mayer, R.E. and Wittrock, M.C. (1996) Problem-Solving Transfer. In: Berliner, D.C. and Calfee, R.C., Eds., Handbook of Educational Psychology, Macmillan, New York, 47-62.

[3] Arslan, R., et al. (2007) Decreasing Math Anxiety in College Students. College Student Journal, 38, 321.

[4] Gilfeather, M. and del Regato, J. (1999) Routine and Non-Routine Problem Solving. Pentathlon Institute, Inc.

[5] Attun, B. (2005) Qualitative Research for Education: An Introduction to Theory 
and Methods. Allyn \& Bacon, Needham Heights, MA.

[6] Vershaffel, L., De Corte, E. and Vierstraete, H. (1999) Upper Elementary School Pupils' Difficulties in Modeling and Solving Nonstandard Additive Word Problems Involving Ordinal Numbers. Journal for Research in Mathematics Education, 30, 265-285. https://doi.org/10.2307/749836

[7] Nescher, J., et al. (1997) Understanding Students' Transitions from Arithmetic to Algebra: A Constructivist Explanation. Paper presented at the Annual meeting of American Educational Research Association, San Francisco, CA.

[8] National Council of Teachers of Mathematics (1989) Curriculum and Evaluation standards Reston.

[9] Mayer, R.E. (1985) Implications of Cognitive Psychology for Instruction in Mathematical Problem Solving. In: Silver, E.A., Ed., Teaching and Learning Mathematical Problem Solving, Lawrence Earlbaum, Hillsdale, NJ, 123-145.

[10] Baroody, A.J. (1993) Problem Solving Reasoning and Communicating, K-8: Helping Children to Think Mathematically. Merrill, New York.

[11] Verschaffel, L. and De Corte, E. (1997) Teaching Realistic Mathematical Modeling in the Elementary School: A Teaching Experiment with Fifth Graders. Journal for Research in Mathematics Education, 28, 577-601. https://doi.org/10.2307/749692

[12] Krulik, S. and Rudnick, J. (1996) The New Sourcebook for Teaching Reasoning and Problem Solving in Junior and Senior High Schools. Allyn and Bacon, Boston, MA.

[13] Van de Walle, J.A. (1993) Elementary School Mathematics: Teaching Developmentally. Longman Publishing Group, New York.

[14] Krulik, S. and Rudnick, J. (1996) The New Sourcebook for Teaching Reasoning and Problem Solving in Junior and Senior High School. Allyn \& Bacon, Needham Heights, MA.

[15] Cai, J. (2003) Singaporean Students' Mathematical Thinking in Problem Solving and Problem Posing: An Exploratory Study. International Journal of Mathematical Education in Science and Technology, 34, 719-737. https://doi.org/10.1080/00207390310001595401

[16] Selden, J., Selden A. and Mason, A. (1994) Even Good Calculus Students Can't Solve Nonroutine Problems. In: Kaput, J.J. and Dubinsky, E., Eds., Research Issues in Undergraduate Mathematics Learning: Preliminary Analyses and Results, Mathematical Association of America, Washington DC, 19-26.

[17] Woodward, J., et al. (2012) Building a Versatile Understanding of Algebraic Variables with a Graphic Calculator. Educational Studies in Mathematics, 41, 265-282.

[18] Harr, T. and Johnson, K. (2002) Problem-Solving Strategies: Crossing the River with Dogs. Key Curriculum Press, USA.

[19] Reif, F., Larkin, J.H. and Brackett, G.C. (1976/1979/1981) Teaching General Learning and Problem-Solving Skills. American Journal of Physics, 44, 212-217. https://doi.org/10.1119/1.10458

[20] Barbu, O. and Beal, C.R. (2010) Effects of Linguistic Complexity and Math Difficulty on Word Problem Solving by English Learners. International Journal of Education, 2, E6. 


\section{Appendix}

Non-Routine Word Problems Actual)

1) The car park at the NEUST is only allowed for cars and motorcycles. A count shows that there are 45 vehicles and 150 wheels in this car park when it is full. How many motorcycles are there when the car park is full?

2) The coach of the tennis team was having problems selecting his team members. He had to choose four players, two men and two women from the six who had tried out. Personal feelings were making it difficult for him.

a) Paul said, "I'll play only if Sarah plays."

b) Sarah said, "I won't play if Eric is on the team."

c) Eric said, "I won't play if David or Linda is chosen."

d) David said, "I'll play only if David or Linda is chosen."

e) Amy had no likes or dislikes."

f) Who will be selected by the coach?

3) In a dancing competition organized by DANZA Club, all the contestants started dancing together. After three minutes, half the people are eliminated. During the next ten minutes half of the remaining were eliminated. At the 15 minute mark, half again were eliminated, and at the 20 minute mark, half of those still remaining were eliminated. In the last two minutes one or more contestant was eliminated leaving a winner of the competition. How many dancers were there in the beginning?

4) Mr. Galang owns a rectangular field with the lengths of its sides 1000 meters and 1500 meters. He split the land among his children in a way each child gets a square field. In this case, what is the least number of children that Mr. Galang has?

5) Bessie hangs out the laundry on a sunny day. It takes 25 minutes for a $3 \mathrm{~kg}$ laundry to dry out. How long does it take the same kind of $9 \mathrm{~kg}$ laundry to dry out under the same weather condition?

6) Cecilia arrived at the concert hall 15 minutes before a concert began. However, due to some technical problems, the concert started 10 minutes later. The whole concert lasted for 2 hours 25 minutes. It was 10:30 pm when Cecilia left the concert hall. At what time did Cecilia arrive at the concert hall? 